\title{
Recent developments in solid lipid nanoparticle and surface-modified solid lipid nanoparticle delivery systems for oral delivery of phyto- bioactive compounds in various chronic diseases
}

This article was published in the following Dove Press journal:

International Journal of Nanomedicine

\author{
Palanivel Ganesan ${ }^{1,2, *}$ \\ Prakash Ramalingam ${ }^{3,4, *}$ \\ Govindarajan \\ Karthivashan ${ }^{1, *}$ \\ Young Tag Ko ${ }^{4}$ \\ Dong-Kug Choi ${ }^{1,2}$
}

'Department of Biotechnology, College of Biomedical and Health Science, Konkuk University, Chungju, Republic of Korea; ${ }^{2}$ Nanotechnology Research Center and Department of Applied Life Science, Konkuk University, Chungju, Republic of Korea; ${ }^{3}$ Department of Pharmaceutical Sciences, Philadelphia College of Pharmacy, University of the Sciences, Philadelphia, PA, USA; ${ }^{4}$ College of Pharmacy, Gachon University, Incheon, Republic of Korea

*These authors contributed equally to this work

\begin{abstract}
Solid lipid nanoparticle (SLN) delivery systems have a wide applicability in the delivery of phyto-bioactive compounds to treat various chronic diseases, including diabetes, cancer, obesity and neurodegenerative diseases. The multiple benefits of SLN delivery include improved stability, smaller particle size, leaching prevention and enhanced lymphatic uptake of the bioactive compounds through oral delivery. However, the burst release makes the SLN delivery systems inadequate for the oral delivery of various phyto-bioactive compounds that can treat such chronic diseases. Recently, the surface-modified SLN (SMSLN) was observed to overcome this limitation for oral delivery of phyto-bioactive compounds, and there is growing evidence of an enhanced uptake of curcumin delivered orally via SMSLNs in the brain. This review focuses on different SLN and SMSLN systems that are useful for oral delivery of phyto-bioactive compounds to treat various chronic diseases.
\end{abstract}

Keywords: solid lipid nanoparticles, surface-modified solid lipid nanoparticles, chronic diseases, phyto-bioactive compounds, chitosan

\section{Introduction}

Solid lipid nanoparticles (SLNs) are lipid-based delivery systems that exist in numerous sizes, ranging from 30 to $1,000 \mathrm{~nm}$. These can be developed using easily degradable lipids. SLNs have multiple advantages than other nano-delivery systems including bypassing the spleen or liver filtration with the particle size of 120-200 nm, lower chronic or acute toxicity due to physiological lipid, enhanced bioavailability and productivity, higher reproducibility, lower organic solvents usage in the preparation, protection of liable phytocompounds or drugs and possibility to incorporate both hydrophilic and hydrophobic compounds. Further, SLNs can be made with highly degradable lipids and hence are biologically safe systems which allow large-scale production, easy sterilization and long storage period. These advantages made the SLNs suitable for the oral delivery of various phyto-bioactive compounds, such as curcumin, resveratrol, quercetin and other polyphenols, to treat several types of chronic diseases..$^{1-6}$ Even though conventional SLNs have several advantages, there is a challenge to oral delivery of bioactive compounds, ${ }^{4,7,8}$ that is, the burst release of the phyto-bioactive compounds in the stomach at a lower $\mathrm{pH}$ of about $1-3$. To overcome this problem, the SLNs are subjected to surface modification to enhance the delivery of the phytobioactive compounds and to prevent the higher release in the stomach. ${ }^{7}$ 
Surface-modified SLNs (SMSLNs) were recently produced using heparin, albumin, polyethylene glycol and polysaccharides to control the oral delivery of phyto-bioactive compounds. Chitosan is highly degradable, presents lower immunogenicity and is suitable for controlled oral delivery of the phyto-bioactive compounds under various $\mathrm{pH}$ conditions. ${ }^{4,9-11}$ The fate of SLNs and modified SLNs (MSLNs) administered through an oral delivery system is shown in Figures 1 and 2. The surface coating of SLNs with chitosan along with modifications in chitosan has many advantages in reducing the $\mathrm{pH}$, such as a sustained release of the bioactive compounds, and a higher positive charge leads to a lower burst release of the SMSLNs. Coating the modified chitosan on SLNs results in the controlled release of these phyto-bioactive compounds in harsh gastric environments, which will be helpful to treat chronic diseases ${ }^{7,8,12,13}$ by improving the efficacy of the therapy. Some SMSLN delivery systems, such as trimethyl chitosan (TMC), showed enhanced delivery of the compounds to the brain in an Alzheimer's mouse model. Further, modification of the chitosan and development of MSLNs are not cost effective. Other advantages of MSLNs including enhanced targeted delivery of the active compounds, ability to cross the blood-brain barrier in neuroinflammatory diseases and long-term storage with bulk production make them an appropriate choice among the other nano-delivery systems. The recent surface modification of SLNs using chitosan and their applicability in chronic diseases are discussed in this review, focusing on SLNs and SMSLNs for oral delivery of the phyto-bioactive compounds and treatment in various in vitro and in vivo chronic disease models.

\section{Role of SLNs in the oral delivery of phyto-bioactive compounds}

SLN is a first-generation nano-delivery system that has been extensively used for sustained release in oral delivery of phytocompounds to treat various chronic diseases. ${ }^{714-19}$ Recently, many new nano-delivery systems have been developed for oral delivery. ${ }^{15-18}$ However, SLN has its own advantages in the bulk production, including a lower production cost, longterm stability and tolerability and biodegradability with lower toxic effects, along with enhanced oral delivery of phytobioactive compounds. Recently, sesamol-loaded SLN was developed with a particle size of about $120 \mathrm{~nm}$, and it exhibited enhanced oral delivery for carbontetrachloride-induced hepatotoxicity in an animal model. The results confirmed that sesamol-loaded SLN has a higher protective effect than free sesamol, with lower irritation and no toxicity. ${ }^{20}$ Further, the

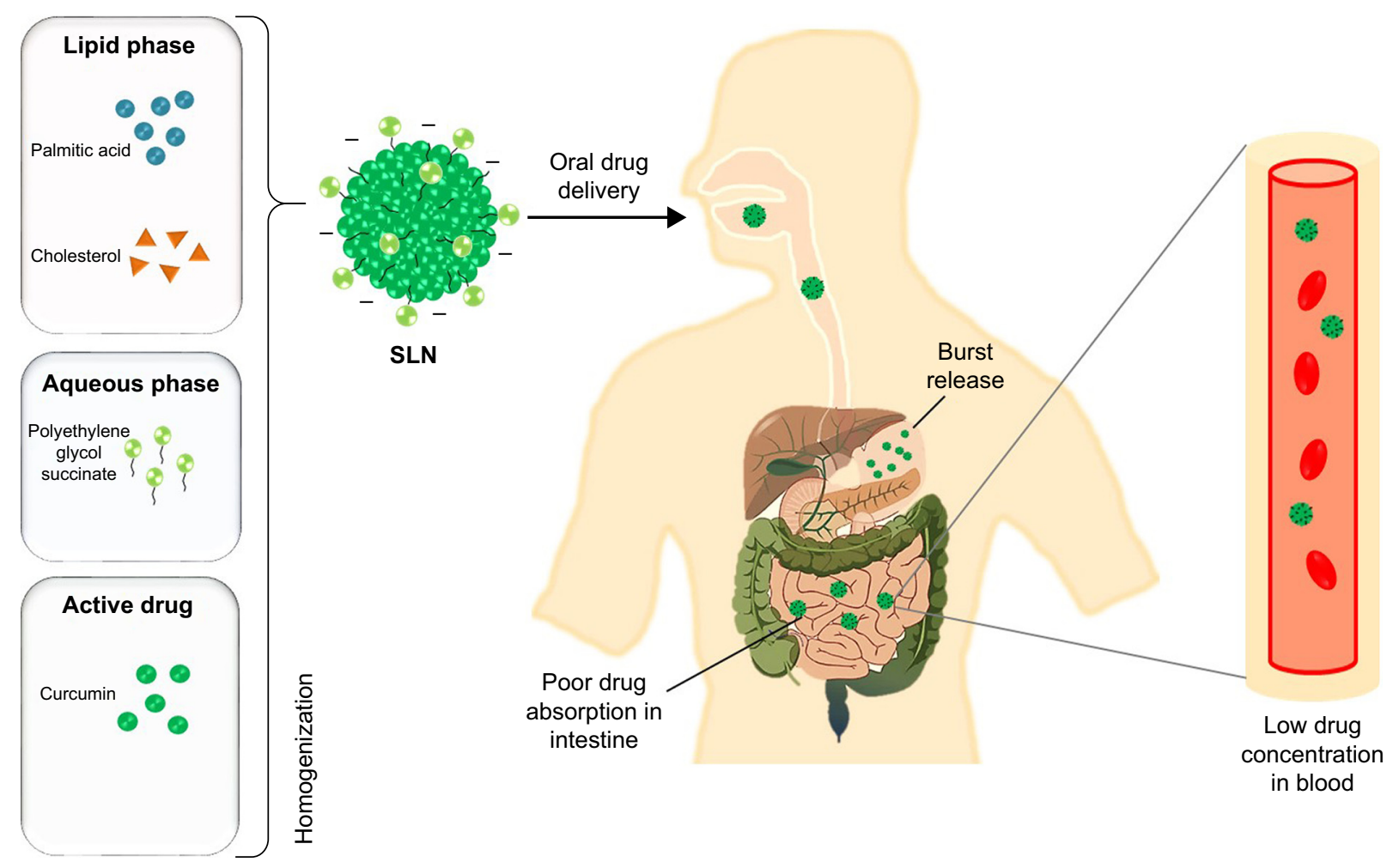

Figure I Schematic representation of the fate of SLN through oral delivery. Abbreviation: SLN, solid lipid nanoparticle. 


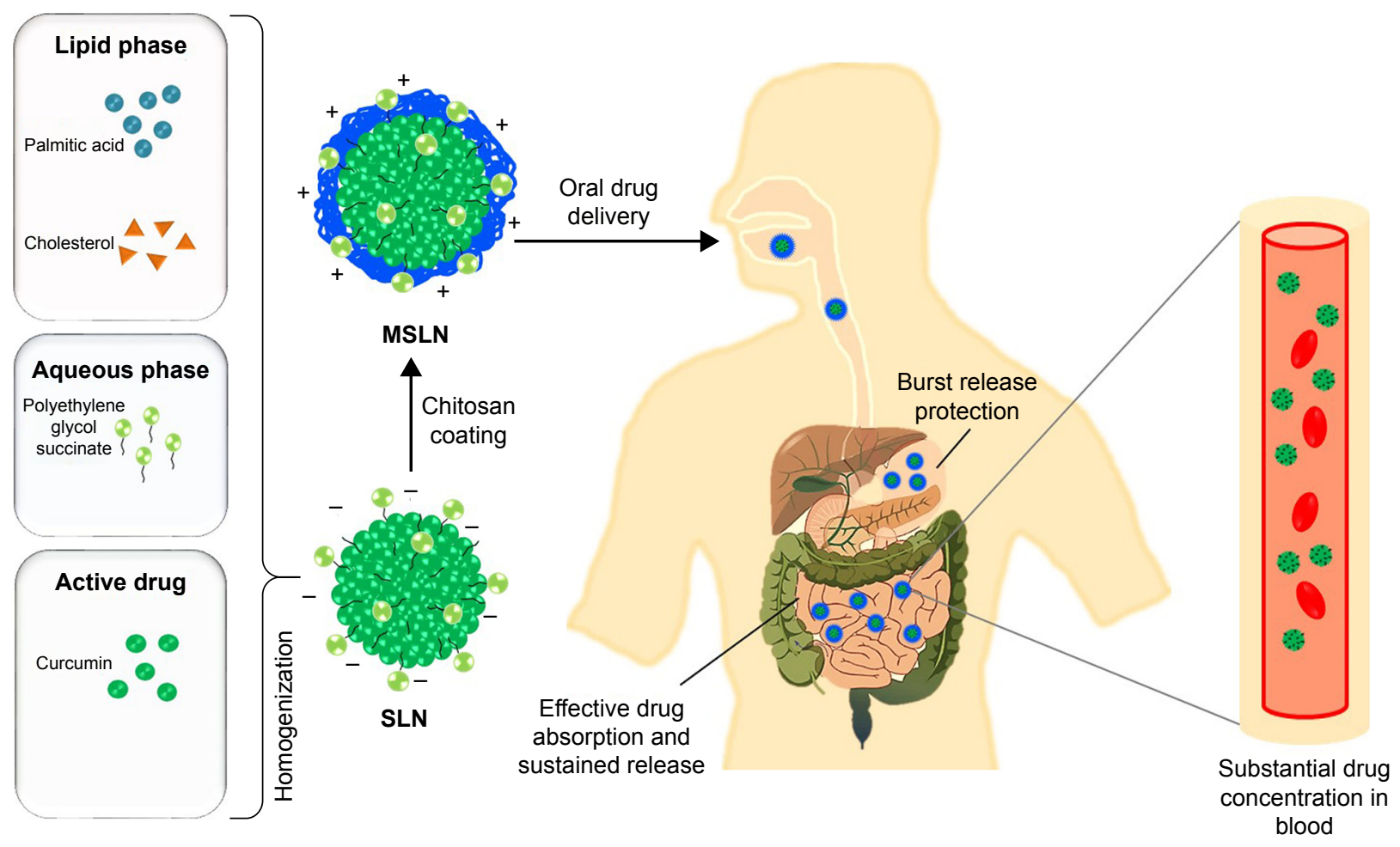

Figure 2 Schematic representation of the fate of MSLN through oral delivery.

Abbreviations: MSLN, modified solid lipid nanoparticle; SLN, solid lipid nanoparticle.

antioxidant potential of sesamol-loaded SLN was higher than that of free sesamol through oral delivery. ${ }^{21}$ Similarly, curcumin-loaded SLN was studied in the cerebral ischemia rat model, and the results indicated 16.4 times greater bioavailability of curcumin in the brain than with free curcumin. The brain bioavailability greatly increased along with a $90 \%$ increase in the cognition of the cerebral ischemic rat group. ${ }^{22}$ Resveratrol was also studied for its sustained bioavailability through oral delivery via resveratrol-loaded SLN with a particle size of about $241 \mathrm{~nm}$ in male Wistar rats. Compared to free resveratrol, lipid core-loaded resveratrol showed two times higher bioavailability in the brain, kidney and liver. ${ }^{23}$ Recently, quercetin-loaded SLN was developed with a particle size of about $172 \mathrm{~nm}$, and a single oral dose showed 3.2 times higher bioavailability than free quercetin along with enhanced osteoprotective effect in a postmenopausal rat model. ${ }^{24}$ Similarly, many other flavonoid-loaded SLNs were studied to assess their efficacy in the delivery of bioactive compounds. Owing to the higher-release behavior of SLN, puerarin-loaded SLN was studied for the cardioprotective effect through intragastric delivery, and it showed 3.1 times higher bioavailability than free puerarin. ${ }^{25}$ The association of resveratrol with lipids was also studied in a stimulated gastrointestinal environment, and it was found to be stable with efficient delivery. Even though the lipid association of other phyto-bioactive compounds may be different, researchers are now highly focusing on modified SLNs for the sustained release of the phyto-bioactive compounds through oral delivery.

\section{SLN formulation and production strategies for the improvement of oral delivery of bioactive compounds}

For the enhanced oral delivery and stability of the phytobioactive compounds through SLNs, their composition of the formulation and their production methods play a critical role. SLN formulation in turns depends on the type of surfactants, lipids, phyto-bioactive compounds, cosurfactant and cryoprotectant which determines the stability and target reachability of the loaded phyto-bioactive compounds. ${ }^{26}$ Various range of lipids like triacylglycerols, waxes, hard fats, palmitic acid and stearic acid are used to fabricate SLNs which have their own advantages as well as disadvantages. In case of curcumin loaded in several types of lipids, the entrapment efficiency increases with increase in the chain length of the hydrocarbon chain. Recently, Aditya et al studied the entrapment efficiency of curcumin in SLNs made with different lipids including 
trimyristin, tristearin and glycerol monosterate and found that glycerol monosterate has greater entrapment efficacy than the other lipids. ${ }^{26,27}$ Further, the entrapment efficiency of phyto-bioactive compounds like curcumin, resveratrol, or genistein also depends on the molecular weight of the type of compounds involved. Increase in the molecular weight decreases the entrapment efficiency of the compounds which in turn leads to lower oral delivery of the phytocompounds. In addition to the lipids selection, surfactants also play a critical role in the formulation of SLNs, by avoiding coalescence during solidification which in turn depends on the type of surfactant involved and its concentration. ${ }^{28-30}$ Further, the production methods also determine the SLN loading capacity and stability of the phyto-bioactive compounds. ${ }^{31,32}$ Various methods like emulsification solvent diffusion, emulsification solvent evaporation, high-pressure homogenization and microfluidization are involved in the production of SLNs. Owing to the lower degradation of sensitive phyto-bioactive compounds like curcumin, lower toxicity, enhanced stability and bulk production of the SLNs, microfluidization and high-pressure homogenization techniques are generally recommended in the production of phyto-bioactive compounds-loaded SLNs.

\section{Absorption mechanisms of phyto- bioactive compounds loaded in SLNs and SMSLNs through oral delivery in various chronic disease models}

Phyto-bioactive compounds loaded in the SLNs and SMSLNs need to be solubilized before absorption in the gastrointestinal tract when chronic diseases are treated through oral delivery. ${ }^{33-38}$ The digestion of SLNs and SMSLNs by stomach enzymes results in SLN and SMSLN emulsion and formation of degradation products that form mixed micelles. These mixed micelles loaded with phyto-bioactive compounds can exhibit enhanced absorption due to their lower particle size. ${ }^{18,39,40}$ In addition, surface modification results in the adhesion of SLNs to the intestine, which can result in longer or prolonged delivery to treat chronic disease. For the above reasons, SLNs loaded with phyto-bioactive compounds can pass through intervillar space or lymphatic system or Peyer's Patch without much loss in the active site of the bioactive compounds. In addition to the transportation of the bioactive compounds, some amount of coated nanoparticles are also transported through ileum absorption. ${ }^{41-43}$ The absorption mechanisms and biodistribution in various organs are shown in Figure 3. Many recent studies have confirmed the enhanced absorption of bioactive compounds through SLNs or SMSLNs to treat diseases including diabetes, cancers, neurological diseases and inflammations, and the effects of SLNs on a few of these diseases are discussed.

\section{Anti-type 2 diabetic effect}

Type 2 diabetes mellitus treatments with phyto-bioactive compounds are used in traditional medicinal systems in India, China and Korea. Various food-grade phytocompounds have shown an enhanced effect in preventing type 2 diabetes mellitus. ${ }^{44-48}$ Curcumin-treated prediabetic patients have shown a beneficial effect in reducing the development of diabetes with 9 months of intervention, along with a higher improvement in the $\beta$-cell functions. ${ }^{49}$ Similarly, a resveratrol supplementation can enhance the antidiabetic effect in humans with a dose of $1 \mathrm{~g}$ for 45 days. ${ }^{50}$ Quercetin is another flavonoid compound that showed a higher antidiabetic effect in streptozotocin-induced diabetic rats. Even though these phyto-bioactive compounds showed a higher antidiabetic effect, a longer duration of treatment was needed. In addition, their efficacy and bioavailability when administered through oral delivery systems were very low. To improve the bioavailability through oral delivery, several macro- or nano-sized colloidal systems have been studied. Among them, SLNs showed an enhanced effect in treating type 2 diabetes through oral delivery. Recently, berberineloaded SLNs with a particle size of $76.8 \mathrm{~nm}$ showed an improved bioavailability with a higher antidiabetic effect in a diabetic mouse model. ${ }^{51}$ This study also confirmed that berberine-loaded SLNs improved the islet function and can thereby effectively reduce diabetes progression. In addition, the same research group also found that the bioavailability of the berberine in the liver was 20 times higher than in blood, which led to a reduction in diabetes-associated complications such as lipolysis enhancement and lipogenesis inhibition. ${ }^{52}$ These studies confirm that delivery of the bioactive compound to the systemic circulation in a highly active way can enhance not only specific activities but also improve the associated complications. The bioavailability of certain other compounds such as curcumin, resveratrol, or quercetin was effectively enhanced through SLN delivery systems, but their activity in a diabetic animal model remains limited. Recently, surface-modified SLNs loaded with curcumin showed a 9.5 times higher bioavailability through oral delivery, ${ }^{7}$ and they can be potentially applied to treat type 2 diabetes.

\section{Anticancer effect}

Phytocompounds have been used to effectively treat various cancers for longer periods of time. ${ }^{53-56}$ However, this effect is not highly appreciable due to a higher loss of bioactivity 


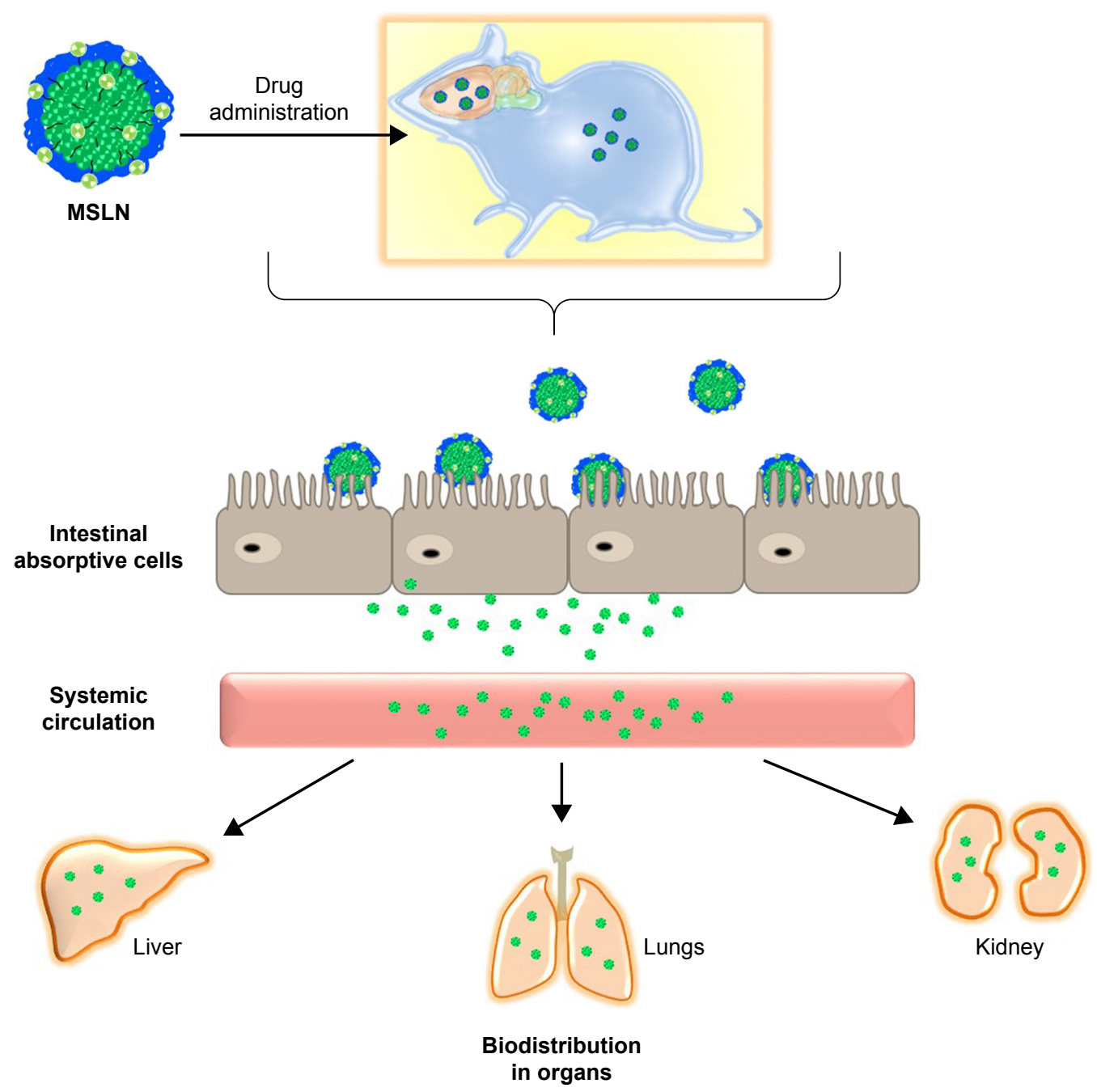

Figure 3 Biodistribution of phytocompounds loaded in MSLN through oral delivery. Abbreviation: MSLN, modified solid lipid nanoparticle.

during oral therapy. Several synthetic medicines have also faced limitations for oral therapy, so lipid-based delivery of their active compounds has been extensively used to develop various cancer treatments. ${ }^{57,58}$ SLNs have been extensively used in many studies to orally deliver bioactive compounds with an enhanced anticancer effect. ${ }^{17,57,59-62}$ Genistein is a phytoestrogen that is extensively used for hormone-related cancers, and it has limited bioavailability. Recently, genisteinloaded solid lipid microparticles (SLMs) with a particle size of $6 \mu \mathrm{m}$ were compared with SLNs with a particle size of about $120 \mathrm{~nm}$ in terms of their bioavailability. Surprisingly, SLMs showed a greater anticancer effect than the SLNs due to a slow disintegration in the intestine as well as the particles reaching the colon. In addition, different sizes of the particles can be used to alter the surface area of genistein to improve its activity. Smaller SLNs can be extensively absorbed in mesenteric vessels, leading to a higher absorption of the bioactive compounds rather than reaching the colon. ${ }^{63}$
In another study, curcumin-loaded SLNs were studied for their antitumor activity through intravenous administration, and curcumin showed a 1.25 times enhanced bioavailability. ${ }^{62}$ Other research groups compared curcumin-loaded SLNs administered via intravenous or oral routes and showed 30 or 16.4 times higher bioavailability of curcumin, respectively. ${ }^{22}$ Thereby, surface modification of SLNs with chitosan or modified chitosan could enhance the bioavailability of curcumin or other compounds in various organs through oral delivery. However, their applicability in various anticancer disease models is still limited. Many in vitro cell studies have shown an enhanced anticancer effect in various cancer models. Recently, berberine-loaded SLNs showed enhanced antitumor effect with a particle size of about $81 \mathrm{~nm}$ in MCF-7 cell lines. ${ }^{64}$ Aloe-emodin is another phytocompound that can be loaded in SLNs, and when prepared with a particle size of about $88 \mathrm{~nm}$, it showed an enhanced anticancer effect to treat breast and hepatoma cancer cell lines. ${ }^{65}$ Resveratrol-loaded 
SLNs with a particle size of about $96 \mathrm{~nm}$ showed an enhanced anticancer effect in HepG2 cells. ${ }^{66}$ Similarly, oridoninloaded SLNs with a particle size of about $108 \mathrm{~nm}$ showed an enhanced antitumor effect in MCF-7 cells. ${ }^{67}$ Various research studies confirm that SLNs could be a potential carrier for various anticancer phyto-bioactive compounds, and further research on oral delivery of those anticancer phyto-bioactive compounds is necessary.

\section{Antiobesity effect}

The antiobesity effect of various phyto-bioactive compounds is well known to function through the inhibition of various cell signaling mechanisms, but these are very complex. In general, obesity is characterized by an increase in the deposition of fat storage adipose cells. A diet rich in various phytochemicals has shown an extensive reduction in the deposition of fat through complex mechanisms. ${ }^{68,69}$ However, the concentration of certain phytochemicals reaching systemic circulation is very low. For instance, green tea catechin is a potential antiobesity compound, but its bioavailability is very low and is limited to $0.15 \mu \mathrm{M}$ of the epigallocatechin gallate (EGCG). ${ }^{70}$ In order to enhance the bioavailability of such phytocompounds, many lipidbased nanodelivery systems with SLNs or MSLNs have been developed to improve the delivery of the bioactive compounds with great potential for an antiobesity effect. Recently, EGCG was successfully loaded in SLNs with a particle size of about 300-400 nm, and it showed a higher stability and greater potential for oral delivery. ${ }^{71}$ It could possibly be used in future as a delivery system to treat obesity-related complications. Zerumbone is another lipophilic compound that is most commonly found in ginger, and has shown an extensive antiobesity effect. ${ }^{72}$ To date, there have been limited attempts to develop SLNs to deliver zerumbone for its antiobesity effect. Resveratrol is also a potential compound that has shown a higher antiobesity effect in various animal studies. ${ }^{73}$ However, it requires a higher dose and prolonged supplementation. Recently, resveratrol-loaded SLNs and MSLNs were studied for their potential bioavailability. However, their roles in antiobesity have not yet been elucidated. Quercetin is another active compound that has shown significant potential for antiobesity in various animal studies. Recently, quercetin-loaded SLNs and chitosan-coated MSLNs were developed with a particle size of about $110 \mathrm{~nm}$, and these showed an enhanced bioavailability of quercetin with a higher stability. ${ }^{74}$ Further research is needed to focus on the oral delivery of SLNs and their antiobesity effect in animal models.

\section{Anticardiovascular effect}

Phyto-bioactive compounds such as resveratrol, curcumin, quercetin and diosgenins have shown an enhanced anticardiovascular effect through their cardioprotective activity. This cardioprotection is achieved through mechanisms such as antihyperlipidemia, antioxidation or platelet aggregation inhibition. ${ }^{75-77}$ However, most phyto-bioactive compounds taken with the diet or through an oral delivery system have exhibited a lower bioavailability in systemic circulation. ${ }^{78-80}$ Recently, many phyto-bioactive compounds showed an improved bioavailability through SLN or MSLN delivery systems, which can further improve their cardioprotective activity. Puerarin is among the most cardioprotective compounds, and its successful loading in SLNs resulted in a higher bioavailability in various organs, especially three times higher in the heart and the brain. ${ }^{81}$ These studies confirm that a higher bioavailability and sustained release of these bioactive compounds can lead to a higher cardioprotective effect. ${ }^{39,194}$ Furthermore, there is no change in the production of the metabolite when given orally. Very recently, flavonoid from Dracocephalum moldavica L. loaded in the SLNs with a particle size of about $104 \mathrm{~nm}$ showed an improved protective effect against myocardial ischemic-reperfusion injury. This could be a base study to prepare another phyto-bioactive compound-loaded SLN with cardioprotective activities. ${ }^{39}$ Hydroxycitric acid (HCA) is a cardioprotective agent that was found in Garcinia cowa, and it undergoes much degradation during processing, leading to the loss of its cardioprotective activity when administered orally. Recently, HCA was successfully loaded in SLNs, which showed 1.3 times higher bioavailability than its free form. ${ }^{82}$ Many phytocompounds loaded in SLNs or MSLNs are yet to be studied for their efficacy in oral delivery along with cardioprotective activity. Many other studies were conducted with a low-molecular-weight heparin-loaded SLNs or MSLNs with a much higher oral bioavailability to improve the cardioprotective activities.

\section{Anti-arthritic effect}

Phyto-bioactive extracts and compounds, such as green tea extract, pomegranate extract, curcumin, resveratrol, celastrol and gamabogic acid, have been extensively used to treat rheumatoid arthritis (RA). ${ }^{83-85}$ These bioactive compounds showed an inhibitory mechanism against inflammatory mediators, thereby preventing cartilage destruction in various animal studies. Besides the protective effect of these bioactive compounds, their bioavailability through oral delivery system is a great challenge for their potential RA treatment. ${ }^{86-88}$ 
To overcome this, recently phytocompounds were loaded in SLNs and MSLNs which showed excellent bioavailability. Piperine-loaded SLNs with a particle size of about $128 \mathrm{~nm}$ showed excellent delivery of such compounds with potential anti-RA activity. ${ }^{89}$ Similarly, hesperidin-loaded SLNs also showed a potential anti-RA effect with a particle size of about $279 \mathrm{~nm}$ in male Wistar rats. In another study, curcuminloaded SLNs also showed an excellent delivery of curcumin in the RA-induced rats with potential anti-inflammatory or antioxidative mechanisms..$^{90}$ Other phytocompounds such as EGCG were also efficiently loaded in SLN systems and showed excellent bioavailability in animal models. This could also be potentially applied to treat RA. Many other bioactive compounds with potential anti-RA activities can also be efficiently loaded in SLN systems ${ }^{91}$ for use in future treatments with nanomedicines. Furthermore, to improve the sustained release of the bioactive compounds, MSLNs can also be developed with specific bioactive compounds with higher anti-RA activities.

\section{Anti-Alzheimer's effect}

Phyto-bioactive compounds-loaded SLNs were recently used to treat Alzheimer's disease (AD), overcoming conventional limitations in treating neurodegenerative diseases. ${ }^{92-96}$ Initially, SLN- or MSLN-loaded bioactive compounds were given intranasally or intravenously, and these showed extensive bioavailability in the brain, thereby preventing inflammation and further progression of AD. ${ }^{97-101}$ Quercetin-loaded SLN with a particle size of about $200 \mathrm{~nm}$ was studied for its efficacy in the AD model, and it showed excellent delivery of quercetin to the brain with a higher antioxidative effect in brain cells. ${ }^{102}$ The transport of bioactive compounds to the brain occurs through the endocytosis of the brain capillaries, and these compounds can thereby cross the blood-brain barrier. In a recent study, piperine-loaded SLNs showed enhanced bioavailability in the brain cells, and can thereby prevent a further prognosis of the AD. The study also revealed that piperine can enhance acetyl cholinesterase activity, reducing the formation of plaques and thereby improving cognitive activity. ${ }^{96}$ Another study investigating ferulic acidloaded SLNs against neurotoxicity found that ferulic acid can be extensively delivered to brain cells and can thereby prevent oxidation without any toxicity. ${ }^{103}$ Curcumin is another potential compound that showed excellent anti-Alzheimeric effect in various in vitro and in vivo studies, ${ }^{104-112}$ but it showed limitations in its bioavailability through oral delivery with a very low content in the brain, and could not achieve a significant potential effect. Therefore, many recent studies were intended to improve the bioavailability of curcumin to the brain through oral delivery via SLNs.

Recently, curcumin-loaded SLN was studied for its potential effect in an aluminum-induced AD model. Curcuminloaded SLN showed excellent delivery of curcumin to the brain, and the bioavailability of curcumin varied from 32 to 155 times in a dose-dependent manner with an enhancement in cognition and the biochemical parameters associated with it. In comparison with free curcumin, treatment with curcumin-loaded SLN showed 73\% higher recovery of the biochemical aspects. This confirmed that curcumin-loaded SLN will be a potential delivery system for the oral delivery of curcumin for AD treatment. ${ }^{113}$ However, to further improve the bioavailability, curcumin-loaded MSLN was recently developed, and it showed improved delivery of the curcumin for AD treatment. Recently, resveratrol has gained more interest to treat $\mathrm{AD}$ due to its greater neuroprotective effect, and many studies confirmed that resveratrol treatment significantly improved the cognition and biochemical parameters. ${ }^{114-123}$ Recently, resveratrol-loaded SLN was studied for its bioavailability and brain delivery. Resveratrol was efficiently delivered to the brain and exhibited its potential bioactivity. To improve the sustained bioavailability, resveratrol-loaded chitosan-coated MSLN was also studied, which showed an enhanced and sustained delivery of resveratrol to the brain. In another study, resveratrol-loaded SLN with functionalized antibody showed excellent cellular uptake compared to normal SLN..$^{93}$ Many other phyto-bioactive compounds loaded onto SLNs or MSLNs are still in the development pipeline with a size suitable for effective transport through the blood-brain barrier, and these can result in higher protection of brain cells to overcome age-related degenerative diseases. ${ }^{195}$

\section{Anti-Parkinson's effect}

Parkinson's disease (PD) is another neurodegenerative disease that occurs most commonly in the elderly due to the loss of the dopaminergic neurons and the activation of microglial cells. ${ }^{124-130}$ Phyto-bioactive compounds have shown an excellent anti-neuroinflammatory effect through various pathways. ${ }^{131-141}$ However, they have limitations in oral delivery due to their extensive first-pass metabolism and difficulty in crossing the blood-brain barrier. Recently, SLN-loaded phyto-bioactive compounds have shown excellent bioavailability through oral delivery and a higher brain bioavailability. ${ }^{107,132,142,143}$ Curcumin is a bioactive compound that has shown an anti-Parkinson effect in various in vitro and in vivo studies. ${ }^{144-152}$ However, its brain bioavailability is limited. Recently, curcumin-loaded SLN was studied for 
its efficacy and brain bioavailability. The bioavailability of curcumin-loaded SLNs or MSLNs in the brain was greatly enhanced, ${ }^{7,8,12}$ which showed its potential for use in treating PD in future. Similarly, resveratrol-loaded SLNs or MSLNs also showed potential for delivery to the brain cells, and can also exert an anti-Parkinson effect. Many recent approaches assessed the brain bioavailability to exert a preventive effect against neuronal loss. Nevertheless, there is still a limited role for SLN- and MSLN-loaded phytocompounds in PD animal models through oral delivery. Many new studies are currently in the pipeline to achieve an anti-Parkinson effect using SLN-loaded phyto-bioactive compounds to prevent neuronal loss and thereby ageing.

\section{Antihepatic effect}

Liver damage is associated with various chronic complications. The liver can be protected using dietary phyto-bioactive compounds, ${ }^{45,153-166}$ but their potential for liver protection through oral delivery systems is very limited. However, SLNloaded phytocompounds showed excellent bioavailability with enhanced liver protection. ${ }^{1,20,52,93,167-170}$ Recently, Ficus benjamina-loaded SLN was studied against the hepatotoxicity, and the results showed a higher delivery of bioactive compounds with enhanced hepatoprotectivity. ${ }^{171}$ Similarly, sesamol-loaded SLN also showed excellent hepatoprotection along with lower irritation when administered through oral delivery. ${ }^{20,21,95,172}$ However, many phytocompounds that have shown excellent hepatoprotection have not yet been studied for their efficacy and bioavailability through SLN or MSLN delivery systems.

\section{Chitosan-based surface modification of SLN delivery systems for the bioavailability of phytocompounds to the target organs}

Owing to the higher release of SLN-loaded phyto-bioactive compounds in the stomach with an acidic $\mathrm{pH}$, surface modification was effectively carried out with mucoadhesive polymers to enhance the sustained release of phyto-bioactive compounds in SLNs. ${ }^{4173-175}$ Chitosan has various advantages over other polymers including lower toxicity, enhanced absorption and high mucoadhesive and antimicrobial properties which enhance the oral delivery of the phyto-bioactive compounds. In order to further enhance the absorption properties of the chitosan-coated SLNs, grafting of chitosan moieties was done through conjugation of amine and hydroxyl groups leading to functional chitosan like TMC. ${ }^{7}$ SLN coated with TMC has excellent properties compared with chitosan which include higher mucoadhesiveness, enhanced delivery and low toxicity. Further, modified chitosan grafted with lipids showed target-specific delivery of the core compounds. For example, palmitic acid-grafted TMC-coated SLNs showed enhanced delivery of the different phytocompounds through controlled release by providing excellent surface environment through nanomicelles. Recently, Ramalingam et al studied the delivery of curcumin to the brain compared to that of free curcumin, chitosan-coated, non-chitosan-coated and TMC-g-palmitic acid-coated SLNs. ${ }^{7}$ Among those, TMC-coated SLNs showed enhanced bioavailability of the curcumin in the brain cells. The same research group also found that resveratrol-loaded TMC-g-palmitic acid-coated SLNs showed 3.8 times higher bioavailability than the resveratrol suspension. In another study, N-carboxymethyl chitosan-coated SLNs showed enhanced bioavailability of curcumin in lymphatic cells. The uptake by the lymphatic cells and the oral bioavailability of the curcumin were found to be 6.3 and 9.5 times higher than that of curcumin suspension. ${ }^{176}$ Based on the above studies, we can confirm that chitosan derivatives can be extensively used to improve the delivery of the phyto-bioactive compounds against various chronic diseases (Table 1).

\section{SLN modified with chitosan and its derivatives, and its bioavailability through oral delivery Chitosan-coated SLNs}

Chitosan-coated SLN is the first-generation modified SLN developed to enhance the delivery of phyto-bioactive

Table I Phyto-bioactive compounds loaded in chitosan-coated solid lipid nanoparticles used in various disease models

\begin{tabular}{|c|c|c|c|}
\hline $\begin{array}{l}\text { Type of chitosan-modified solid } \\
\text { lipid nanoparticles }\end{array}$ & $\begin{array}{l}\text { Bioactive } \\
\text { compounds }\end{array}$ & Disease models & References \\
\hline \multirow[t]{4}{*}{ Chitosan-coated solid lipid nanoparticles } & Curcumin & Pancreatic cancer models & Thakkar et al ${ }^{181}$ \\
\hline & Resveratrol & Brain bioavailability studies & Ramalingam and $\mathrm{Ko}^{13}$ \\
\hline & Caffeic acid & Oral bioavailability studies & Fathi et al ${ }^{183}$ \\
\hline & Ferulic acid & Pancreatic cancer models & Thakkar et al $\left.\right|^{181}$ \\
\hline Trimethyl chitosan-coated solid lipid & Curcumin & Brain bioavailability studies & Ramalingam and $\mathrm{Ko}^{7}$ \\
\hline nanoparticles & Resveratrol & Brain bioavailability studies & Ramalingam and $\mathrm{Ko}^{12,13}$ \\
\hline $\begin{array}{l}\text { N-trimethyl chitosan-g-palmitic acid } \\
\text { surface-modified solid lipid nanoparticles }\end{array}$ & Resveratrol & Brain bioavailability studies & Ramalingam and $\mathrm{Ko}^{12}$ \\
\hline
\end{tabular}


compounds. Various properties of chitosan, such as high mucoadhesion, cationic nature, low toxicity and high bioavailability, have resulted in more researchers using this polysaccharide as a coating for SLNs to improve the delivery of bioactive compounds. ${ }^{4,19,175,177}$ Chitosan-coated SLN was also used in other delivery routes including nasal, vaginal and skin, due to its enhanced and sustained delivery. ${ }^{19,178-180}$ Based on the type of chitosan and lipids involved, the application and delivery routes vary. In oral delivery, chitosan-coated SLN is preferred for its mucoadhesion and sustained release. Although many commercial drugs have been extensively studied for use with chitosan-coated SLNs for sustained oral delivery, ${ }^{174,177,180,181}$ there are few studies on phyto-bioactive compound loading. Recently, ferulic acid-loaded chitosancoated SLNs were studied to treat pancreatic cancer, and these showed an enhanced effect via oral delivery. Similarly, chitosan-coated SLNs loaded with curcumin showed a sustained release of curcumin in various organs. Furthermore, toxicity studies were conducted for certain drugs in combination with curcumin in chitosan-coated SLNs, and the results indicated no toxicity during pancreatic cancer treatment. ${ }^{182}$ In another study, resveratol loaded in chitosancoated SLNs also showed a higher bioavailability in animal models. Similarly, caffeic acid-loaded SLNs coated with alginate chitosan showed higher antioxidant activity and sustained release. ${ }^{183}$

\section{TMC-coated SLNs}

TMC-coated SLN is another modified SLN that overcomes the drawbacks of chitosan-coated SLN by increasing the solubility over a broad range of $\mathrm{pH}$, improving the mucoadhesion and achieving a sustained release of the bioactive compounds in the SLN during oral delivery. ${ }^{184-186}$ Many early studies were conducted to deliver various drugs, including insulin, vaccines and proteins via sustained delivery with TMC-coated SLNs to enhance the biomedical effects in treating various chronic diseases. ${ }^{187,196-198}$ Fewer studies were conducted on the delivery of phytocompounds through TMC-coated SLNs. ${ }^{7,12}$ A recent study report on the delivery of curcumin to the brain through TMC-coated SLNs showed sustained delivery to the brain through paracellular transport, and this presents a potential treatment for AD models. ${ }^{7}$ The same research group also performed a study with resveratrol as a core compound and found 3.8 times higher delivery of the resveratrol to the target organ through oral delivery. ${ }^{12}$ These studies show a pathway for future studies of various phyto-bioactive compounds for sustained release via oral delivery and improved bioavailability to treat various diseases.

\section{Hydroxypropyl trimethyl ammonium chloride chitosan (HACC)-modified SLNs}

HACC-modified SLN is another modified chitosan-loaded SLN that was recently developed to improve the stability in the gastrointestinal environment for sustained release. ${ }^{188-192}$ A recent study with docetaxel showed that HACC-modified chitosan administered orally exhibits a higher drug bioavailability via various absorption mechanisms including transcellular, paracellular and $\mathrm{M}$ cell uptake. ${ }^{193}$ Interestingly, the study also found that HACC-modified SLNs showed a higher uptake of the drug in the Peyer's Patches than normal cells. The same research group also showed that HACC-modified SLNs with a uniform particle size achieved enhanced bioavailability with around 2.45 times increase of the drug through oral delivery. ${ }^{187}$ In addition, the toxicity of the HACC-modified SLNs was also studied in Caco-2 cells, and the results showed no toxic effect and no irritation in the mucosa of the rats. This study confirmed that there is a chance of increase in the bioavailability of phyto-bioactive compounds like curcumin, quercetin and resveratrol through HACC-modified SLNs, which will be the scope for future studies on enhanced delivery. Figure 4 shows the mucoadhesion and bioavailability of the phytocompounds loaded in the SLNs or MSLNs.

\section{Challenges associated with SLNs and MSLNs in the food systems}

Even though SLN and MSLN delivery systems try to accomplish the criteria required for the enhanced delivery of the phyto-bioactive compounds, it is not possible to use a single delivery system for all the phyto-bioactive compounds. However, both systems have unique advantages in both food and pharmaceutical applications like use of high food-grade lipids, bulk production with lower production cost and higher loading capacity in comparison to the food bioactive compounds. The incorporation of SLNs or MSLNs in the food particles, their physiological changes in the food systems during storage, and toxicity of these systems to the target organs are yet to be studied. The research in these aspects will increase the utilization of the SLNs or MSLNs in the food products. Food-based medicine will be a greater demand soon owing to the toxicity of various synthetic medicines. These systems could efficiently deliver the phytobioactive compounds along with the nutrients, and they will be helpful in the development of fortified food products or functional foods in future. In addition, MSLN development is not cost effective, and further research is necessary in the development of low-cost chitosan and modified chitosan for their effective usage and research in the toxicological 


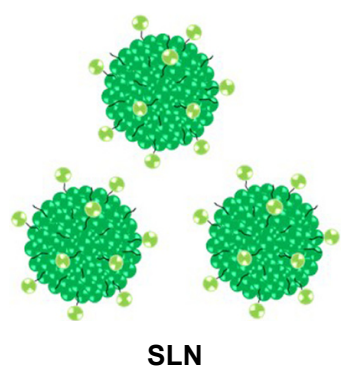
Mucus
layer

SLN

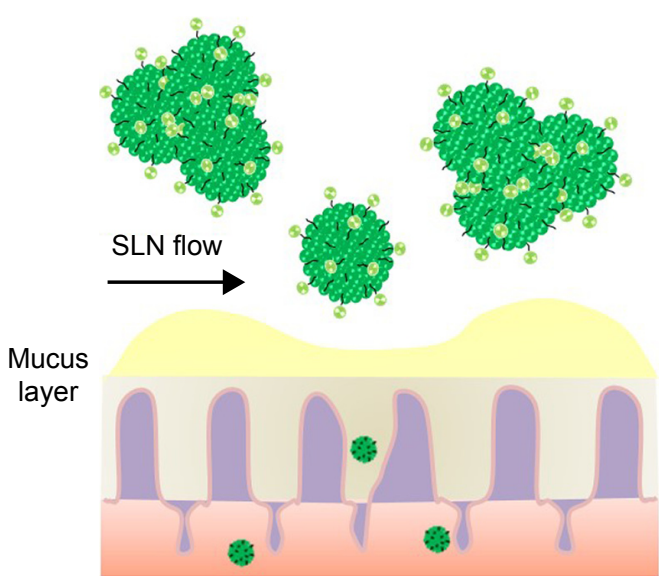

Poor mucoadhesion of SLN

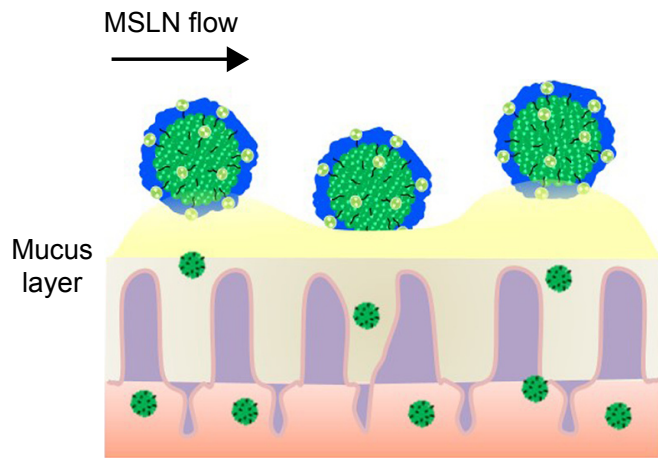

Higher mucoadhesion of MSLN

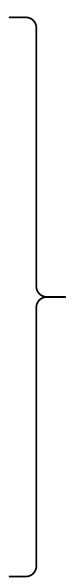

Poor bioavailability in

circulation



Enhanced bioavailability in circulation

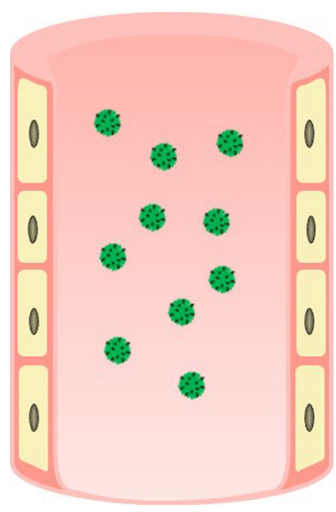

Figure 4 Schematic representation of mucoadhesion of SLN or MSLN through oral delivery.

Abbreviations: MSLN, modified solid lipid nanoparticle; SLN, solid lipid nanoparticle.

aspects could widen their applications in many other associated industries.

\section{Conclusion}

SLNs and MSLNs are promising colloidal delivery systems that help deliver phytocompounds to various organs, including the brain, via oral delivery. The bioavailability of these phytocompounds loaded in SLNs has been found to be about 5-10 times greater than that of their native form. Furthermore, the sustained release of these phyto-bioactive compounds through oral delivery can also be achieved through surface modification of the SLNs, which opens the way for development of many new phytocompounds loaded onto SLNs or MSLNs to treat various chronic diseases. The sustained and improved delivery of phyto-bioactive compounds via oral delivery is a focus of future development in nanomedicine.

\section{Acknowledgment}

This study was supported by the Basic Science Research Program through the National Research Foundation of Korea (NRF) funded by the Ministry of Education, Science, and Technology (NRF-2017R1C1B2010276 and NRF2017R1A2A2A07001035).

\section{Disclosure}

The authors report no conflicts of interest in this work.

\section{References}

1. Ayan AK, Yenilmez A, Eroglu H. Evaluation of radiolabeled curcuminloaded solid lipid nanoparticles usage as an imaging agent in liver-spleen scintigraphy. Mater Sci Eng C Mater Biol Appl. 2017;75:663-670.

2. Comoglu T, Arisoy S, Akkus ZB. Nanocarriers for effective brain drug delivery. Curr Top Med Chem. 2017;17(13):1490-1506.

3. Couto R, Alvarez V, Temelli F. Encapsulation of Vitamin B2 in solid lipid nanoparticles using supercritical $\mathrm{CO}_{2}$. J Supercrit Fluids. 2017; 120:432-442.

4. Sandri G, Motta S, Bonferoni MC, et al. Chitosan-coupled solid lipid nanoparticles: tuning nanostructure and mucoadhesion. Eur J Pharm Biopharm. 2017;110:13-18.

5. Pistollato F, Bremer-Hoffmann S, Basso G, et al. Targeting glioblastoma with the use of phytocompounds and nanoparticles. Target Oncol. 2015; 11(1):1-16.

6. Pistollato F, Giampieri F, Battino M. The use of plant-derived bioactive compounds to target cancer stem cells and modulate tumor microenvironment. Food Chem Toxicol. 2015;75:58-70.

7. Ramalingam P, Ko YT. Enhanced oral delivery of curcumin from N-trimethyl chitosan surface-modified solid lipid nanoparticles: pharmacokinetic and brain distribution evaluations. Pharm Res. 2015;32(2):389-402. 
8. Ramalingam P, Yoo SW, Ko YT. Nanodelivery systems based on mucoadhesive polymer coated solid lipid nanoparticles to improve the oral intake of food curcumin. Food Res Int. 2016;84:113-119.

9. Lee WH, Loo CY, Young PM, Traini D, Mason RS, Rohanizadeh R. Recent advances in curcumin nanoformulation for cancer therapy. Expert Opin Drug Deliv. 2014;11(8):1183-1201.

10. Niu Z, Conejos-Sanchez I, Griffin BT, O'Driscoll CM, Alonso MJ. Lipid-based nanocarriers for oral peptide delivery. Adv Drug Deliv Rev. 2016;106(Pt B):337-354.

11. Raja MA, Zeenat S, Arif M, Liu C. Self-assembled nanoparticles based on amphiphilic chitosan derivative and arginine for oral curcumin delivery. Int J Nanomedicine. 2016;11:4397-4412.

12. Ramalingam P, Ko YT. Improved oral delivery of resveratrol from $\mathrm{N}$-trimethyl chitosan-g-palmitic acid surface-modified solid lipid nanoparticles. Colloids Surf B Biointerfaces. 2016;139:52-61.

13. Ramalingam $P$, Ko YT. Validated LC-MS/MS method for simultaneous quantification of resveratrol levels in mouse plasma and brain and its application to pharmacokinetic and brain distribution studies. J Pharm Biomed Anal. 2016;119:71-75.

14. Ikeuchi-Takahashi $Y$, Ishihara $C$, Onishi H. Formulation and evaluation of morin-loaded solid lipid nanoparticles. Biol Pharm Bull. 2016; 39(9):1514-1522.

15. Grandhi BK, Thakkar A, Wang J, Prabhu S. A novel combinatorial nanotechnology-based oral chemopreventive regimen demonstrates significant suppression of pancreatic cancer neoplastic lesions. Cancer Prev Res (Phila). 2013;6(10):1015-1025.

16. Kakkar V, Mishra AK, Chuttani K, Kaur IP. Proof of concept studies to confirm the delivery of curcumin loaded solid lipid nanoparticles (C-SLNs) to brain. Int J Pharm. 2013;448(2):354-359.

17. Liu J, Chen S, Lv L, Song L, Guo S, Huang S. Recent progress in studying curcumin and its nano-preparations for cancer therapy. Curr Pharm Des. 2013;19(11):1974-1993.

18. Shome S, Talukdar AD, Choudhury MD, Bhattacharya MK, Upadhyaya H. Curcumin as potential therapeutic natural product: a nanobiotechnological perspective. J Pharm Pharmacol. 2016;68(12): 1481-1500.

19. Vijayakumar A, Baskaran R, Jang YS, Oh SH, Yoo BK. Quercetinloaded solid lipid nanoparticle dispersion with improved physicochemical properties and cellular uptake. AAPS PharmSciTech. 2017; 18(3):875-883.

20. Singh N, Khullar N, Kakkar V, Kaur IP. Sesamol loaded solid lipid nanoparticles: a promising intervention for control of carbon tetrachloride induced hepatotoxicity. BMC Complement Altern Med. 2015; 15:142.

21. Singh N, Khullar N, Kakkar V, Kaur IP. Hepatoprotective effects of sesamol loaded solid lipid nanoparticles in carbon tetrachloride induced sub-chronic hepatotoxicity in rats. Environ Toxicol. 2016; 31(5):520-532.

22. Kakkar V, Muppu SK, Chopra K, Kaur IP. Curcumin loaded solid lipid nanoparticles: an efficient formulation approach for cerebral ischemic reperfusion injury in rats. Eur J Pharm Biopharm. 2013;85(3 Pt A) 339-345.

23. Frozza RL, Bernardi A, Paese K, et al. Characterization of trans-resveratrol-loaded lipid-core nanocapsules and tissue distribution studies in rats. J Biomed Nanotechnol. 2010;6(6):694-703.

24. Ahmad N, Banala VT, Kushwaha P, et al. Quercetin-loaded solid lipid nanoparticles improve osteoprotective activity in an ovariectomized rat model: a preventive strategy for post-menopausal osteoporosis. RSC Adv. 2016;6(100):97613-97628.

25. Luo CF, Yuan M, Chen MS, et al. Pharmacokinetics, tissue distribution and relative bioavailability of puerarin solid lipid nanoparticles following oral administration. Int J Pharm. 2011;410(1-2):138-144

26. Aditya NP, Ko S. Solid lipid nanoparticles (SLNs): delivery vehicles for food bioactives. RSC Adv. 2015;5(39):30902-30911.

27. Aditya NP, Patankar S, Madhusudhan B, Murthy RSR, Souto EB Arthemeter-loaded lipid nanoparticles produced by modified thin-film hydration: pharmacokinetics, toxicological and in vivo anti-malarial activity. Eur J Pharm Sci. 2010;40(5):448-455.
28. Aditya NP, Aditya S, Yang H, Kim HW, Park SO, Ko S. Co-delivery of hydrophobic curcumin and hydrophilic catechin by a water-in-oilin-water double emulsion. Food Chem. 2015;173:7-13.

29. Aditya NP, Shim M, Yang H, Lee Y, Ko S. Antiangiogenic effect of combined treatment with curcumin and genistein on human prostate cancer cell line. J Funct Foods. 2014;8:204-213.

30. Choi KO, Aditya NP, Ko S. Effect of aqueous $\mathrm{pH}$ and electrolyte concentration on structure, stability and flow behavior of non-ionic surfactant based solid lipid nanoparticles. Food Chem. 2014;147:239-244.

31. Aditya NP, Aditya S, Yang HJ, et al. Curcumin and catechin co-loaded water-in-oil-in-water emulsion and its beverage application. $J$ Funct Foods. 2015;15:35-43.

32. Aditya NP, Macedo AS, Doktorovov S, et al. Development and evaluation of lipid nanocarriers for quercetin delivery: a comparative study of solid lipid nanoparticles (SLN), nanostructured lipid carriers (NLC), and lipid nanoemulsions (LNE). LWT Food Sci Technol. 2014;59(1):115-121.

33. Ji P, Yu T, Liu Y, et al. Naringenin-loaded solid lipid nanoparticles: preparation, controlled delivery, cellular uptake, and pulmonary pharmacokinetics. Drug Des Devel Ther. 2016;10:911-925.

34. Kumar P, Sharma G, Kumar R, et al. Vitamin-derived nanolipoidal carriers for brain delivery of dimethyl fumarate: a novel approach with preclinical evidence. ACS Chem Neurosci. 2017;8(6):1390-1396.

35. Lingling G, Yuan Z, Weigen L. Preparation, optimization, characterization and in vivo pharmacokinetic study of asiatic acid tromethamine salt-loaded solid lipid nanoparticles. Drug Dev Ind Pharm. 2016;42(8): $1325-1333$.

36. Madureira AR, Campos D, Gullon B, et al. Fermentation of bioactive solid lipid nanoparticles by human gut microflora. Food Funct. 2016;7(1): 516-529.

37. Neves AR, Martins S, Segundo MA, Reis S. Nanoscale delivery of resveratrol towards enhancement of supplements and nutraceuticals. Nutrients. 2016;8(3):131.

38. Siafaka PI, Ustundag Okur N, Karavas E, Bikiaris DN. Surface modified multifunctional and stimuli responsive nanoparticles for drug targeting: current status and uses. Int J Mol Sci. 2016;17(9).

39. Tan ME, He CH, Jiang W, et al. Development of solid lipid nanoparticles containing total flavonoid extract from Dracocephalum moldavica L. and their therapeutic effect against myocardial ischemia-reperfusion injury in rats. Int J Nanomedicine. 2017;12:3253-3265.

40. Wang T, Ma X, Lei Y, Luo Y. Solid lipid nanoparticles coated with cross-linked polymeric double layer for oral delivery of curcumin. Colloids Surf B Biointerfaces. 2016;148:1-11.

41. Dening TJ, Rao S, Thomas N, Prestidge CA. Oral nanomedicine approaches for the treatment of psychiatric illnesses. J Control Release. 2016;223:137-156.

42. Ma Y, He H, Xia F, et al. In vivo fate of lipid-silybin conjugate nanoparticles: implications on enhanced oral bioavailability. Nanomedicine. 2017;13(6):2643-2654.

43. Nunes S, Madureira AR, Campos D, et al. Solid lipid nanoparticles as oral delivery systems of phenolic compounds: overcoming pharmacokinetic limitations for nutraceutical applications. Crit Rev Food Sci Nutr. 2017;57(9):1863-1873.

44. Anand K, Tiloke C, Naidoo P, Chuturgoon AA. Phytonanotherapy for management of diabetes using green synthesis nanoparticles. J Photochem Photobiol B. 2017;173:626-639.

45. Bulle S, Reddyvari H, Nallanchakravarthula V, Vaddi DR. Therapeutic potential of Pterocarpus santalinus L.: an update. Pharmacogn Rev. 2016;10(19):43-49.

46. Chen CY, Chiu FY, Lin Y, Huang WJ, Hsieh PS, Hsu FL. Chemical constituents analysis and antidiabetic activity validation of four fern species from Taiwan. Int J Mol Sci. 2015;16(2):2497-2516.

47. Dey P, Saha MR, Chowdhuri SR, et al. Assessment of anti-diabetic activity of an ethnopharmacological plant Nerium oleander through alloxan induced diabetes in mice. $J$ Ethnopharmacol. 2015;161: $128-137$.

48. Singh AK, Jatwa R, Purohit A, Ram H. Synthetic and phytocompounds based dipeptidyl peptidase-IV (DPP-IV) inhibitors for therapeutics of diabetes. J Asian Nat Prod Res. 2017;19(10):1036-1045. 
49. Chuengsamarn S, Rattanamongkolgul S, Luechapudiporn R, Phisalaphong C, Jirawatnotai S. Curcumin extract for prevention of type 2 diabetes. Diabetes Care. 2012;35(11):2121-2127.

50. Movahed A, Nabipour I, Lieben Louis X, et al. Antihyperglycemic effects of short term resveratrol supplementation in type 2 diabetic patients. Evid Based Complement Alternat Med. 2013;2013:851267.

51. Xue M, Yang MX, Zhang W, et al. Characterization, pharmacokinetics, and hypoglycemic effect of berberine loaded solid lipid nanoparticles. Int J Nanomedicine. 2013;8:4677-4687.

52. Xue M, Zhang L, Yang MX, et al. Berberine-loaded solid lipid nanoparticles are concentrated in the liver and ameliorate hepatosteatosis in $\mathrm{db} / \mathrm{db}$ mice. Int J Nanomedicine. 2015;10:5049-5057.

53. Chen SS, Michael A, Butler-Manuel SA. Advances in the treatment of ovarian cancer: a potential role of antiinflammatory phytochemicals. Discov Med. 2012;13(68):7-17.

54. Mahata S, Maru S, Shukla S, et al. Anticancer property of Bryophyllum pinnata (Lam.) Oken. leaf on human cervical cancer cells. BMC Complement Altern Med. 2012;12:15.

55. Nie Q, Xing M, Hu J, Hu X, Nie S, Xie M. Metabolism and health effects of phyto-estrogens. Crit Rev Food Sci Nutr. 2017;57(11):2432-2454.

56. Rani N, Velan LP, Vijaykumar S, Arunachalam A. An insight into the potentially old-wonder molecule-quercetin: the perspectives in foresee. Chin J Integr Med. Epub 2015 Sep 9.

57. Davatgaran-Taghipour Y, Masoomzadeh S, Farzaei MH, et al. Polyphenol nanoformulations for cancer therapy: experimental evidence and clinical perspective. Int J Nanomedicine. 2017;12:2689-2702.

58. Park JS, Ahn EY, Park Y. Asymmetric dumbbell-shaped silver nanoparticles and spherical gold nanoparticles green-synthesized by mangosteen (Garcinia mangostana) pericarp waste extracts. Int J Nanomedicine. 2017; 12:6895-6908.

59. Hazzah HA, Farid RM, Nasra MM, et al. A new approach for treatment of precancerous lesions with curcumin solid-lipid nanoparticleloaded gels: in vitro and clinical evaluation. Drug Deliv. 2016;23(4): 1409-1419.

60. Li C, Zhang J, Zu YJ, et al. Biocompatible and biodegradable nanoparticles for enhancement of anti-cancer activities of phytochemicals. Chin J Nat Med. 2015;13(9):641-652.

61. Naksuriya O, Okonogi S, Schiffelers RM, Hennink WE. Curcumin nanoformulations: a review of pharmaceutical properties and preclinical studies and clinical data related to cancer treatment. Biomaterials. 2014;35(10):3365-3383.

62. Sun J, Bi C, Chan HM, Sun S, Zhang Q, Zheng Y. Curcumin-loaded solid lipid nanoparticles have prolonged in vitro antitumour activity, cellular uptake and improved in vivo bioavailability. Colloids Surf B Biointerfaces. 2013;111:367-375.

63. Kim JT, Barua S, Kim H, et al. Absorption study of genistein using solid lipid microparticles and nanoparticles: control of oral bioavailability by particle sizes. Biomol Ther (Seoul). 2017;25(4):452-459.

64. Wang L, Li H, Wang S, et al. Enhancing the antitumor activity of berberine hydrochloride by solid lipid nanoparticle encapsulation. AAPS PharmSciTech. 2014;15(4):834-844.

65. Chen R, Wang S, Zhang J, Chen M, Wang Y. Aloe-emodin loaded solid lipid nanoparticles: formulation design and in vitro anti-cancer study. Drug Deliv. 2014;22(5):666-674.

66. Zhang QH, Xiong QP, Shi YY, Zhang DY. [Study on preparation and characterization of resveratrol solid lipid nanoparticles and its anticancer effects in vitro]. Zhong Yao Cai. 2010;33(12):1929-1932. Chinese [with English abstract].

67. Wang L, Wang S, Chen R, et al. Oridonin loaded solid lipid nanoparticles enhanced antitumor activity in MCF-7 cells. J Nanomater. 2014; 2014:903646

68. Jin Q, Yu H, Li P. The evaluation and utilization of marine-derived bioactive compounds with anti-obesity effect. Curr Med Chem. Epub 2017 Jun 1.

69. Pan MH, Tung YC, Yang G, Li S, Ho CT. Molecular mechanisms of the anti-obesity effect of bioactive compounds in tea and coffee. Food Funct. 2016;7(11):4481-4491.
70. Mereles D, Hunstein W. Epigallocatechin-3-gallate (EGCG) for clinical trials: more pitfalls than promises? Int J Mol Sci. 2011;12(9):5592-5603.

71. Frias I, Neves AR, Pinheiro M, Reis S. Design, development, and characterization of lipid nanocarriers-based epigallocatechin gallate delivery system for preventive and therapeutic supplementation. Drug Des Devel Ther. 2016;10:3519-3528.

72. Hemn HO, Noordin MM, Rahman HS, Hazilawati H, Zuki A, Chartrand MS. Antihypercholesterolemic and antioxidant efficacies of zerumbone on the formation, development, and establishment of atherosclerosis in cholesterol-fed rabbits. Drug Des Devel Ther. 2015; 9:4173-4208.

73. Chang CC, Lin KY, Peng KY, Day YJ, Hung LM. Resveratrol exerts anti-obesity effects in high-fat diet obese mice and displays differential dosage effects on cytotoxicity, differentiation, and lipolysis in 3T3-L1 cells. Endocr J. 2016;63(2):169-178.

74. Vijayakumar A, Baskaran R, Jang YS, Oh SH, Yoo BK. Quercetin-loaded solid lipid nanoparticle dispersion with improved physicochemical properties and cellular uptake. AAPS PharmSciTech. 2016;18(3):875-883.

75. Olas B. Sea buckthorn as a source of important bioactive compounds in cardiovascular diseases. Food Chem Toxicol. 2016;97:199-204.

76. Rangel-Huerta OD, Pastor-Villaescusa B, Aguilera CM, Gil A. A systematic review of the efficacy of bioactive compounds in cardiovascular disease: phenolic compounds. Nutrients. 2015;7(7):5177-5216.

77. Sola R, Valls RM, Puzo J, et al. Effects of poly-bioactive compounds on lipid profile and body weight in a moderately hypercholesterolemic population with low cardiovascular disease risk: a multicenter randomized trial. PLoS One. 2014;9(8):e101978.

78. Malaguti M, Angeloni C, Hrelia S. Nutraceutical bioactive compounds promote healthspan counteracting cardiovascular diseases. J Am Coll Nutr. 2015;34 Suppl 1:22-27.

79. Pastor-Villaescusa B, Rangel-Huerta OD, Aguilera CM, Gil A. A systematic review of the efficacy of bioactive compounds in cardiovascular disease: carbohydrates, active lipids and nitrogen compounds. Ann Nutr Metab. 2015;66(2-3):168-181.

80. Scolaro B, Soo Jin Kim H, de Castro IA. Bioactive compounds as an alternative for drug co-therapy: overcoming challenges in cardiovascular disease prevention. Crit Rev Food Sci Nutr. Epub 2016 Nov 10:1-14.

81. Luo CF, Chen MS, Professor Y, et al. Metabolic profile of puerarin in rats after intragastric administration of puerarin solid lipid nanoparticles. Int J Nanomedicine. 2013;8:933-940.

82. Ezhilarasi PN, Muthukumar SP, Anandharamakrishnan C. Solid lipid nanoparticle enhances bioavailability of hydroxycitric acid compared to a microparticle delivery system. RSC Adv. 2016;6(59):53784-53793.

83. Gupta SC, Tyagi AK, Deshmukh-Taskar P, Hinojosa M, Prasad S, Aggarwal BB. Downregulation of tumor necrosis factor and other proinflammatory biomarkers by polyphenols. Arch Biochem Biophys. 2014;559:91-99.

84. Khalife S, Zafarullah M. Molecular targets of natural health products in arthritis. Arthritis Res Ther. 2011;13(1):102.

85. Rahman M, Beg S, Verma A, et al. Phytoconstituents as pharmacotherapeutics in rheumatoid arthritis: challenges and scope of nano/ submicromedicine in its effective delivery. J Pharm Pharmacol. 2017; 69(1):1-14.

86. Mobasheri A, Henrotin Y, Biesalski HK, Shakibaei M. Scientific evidence and rationale for the development of curcumin and resveratrol as nutraceutricals for joint health. Int J Mol Sci. 2012;13(4):4202-4232.

87. Recio MC, Andujar I, Rios JL. Anti-inflammatory agents from plants: progress and potential. Curr Med Chem. 2012;19(14):2088-2103.

88. Shakibaei M, Mobasheri A, Buhrmann C. Curcumin synergizes with resveratrol to stimulate the MAPK signaling pathway in human articular chondrocytes in vitro. Genes Nutr. 2011;6(2):171-179.

89. Bhalekar MR, Madgulkar AR, Desale PS, Marium G. Formulation of piperine solid lipid nanoparticles (SLN) for treatment of rheumatoid arthritis. Drug Dev Ind Pharm. 2017;43(6):1003-1010.

90. Arora R, Kuhad A, Kaur IP, Chopra K. Curcumin loaded solid lipid nanoparticles ameliorate adjuvant-induced arthritis in rats. Eur J Pain. 2015;19(7):940-952. 
91. Chen J, Wei N, Lopez-Garcia M, et al. Development and evaluation of resveratrol, Vitamin E, and epigallocatechin gallate loaded lipid nanoparticles for skin care applications. Eur J Pharm Biopharm. 2017; 117:286-291.

92. Fonseca-Santos B, Gremiao MP, Chorilli M. Nanotechnology-based drug delivery systems for the treatment of Alzheimer's disease. Int $J$ Nanomedicine. 2015;10:4981-5003.

93. Loureiro JA, Andrade S, Duarte A, et al. Resveratrol and grape extractloaded solid lipid nanoparticles for the treatment of Alzheimer's disease. Molecules. 2017;22(2).

94. Picone P, Bondi ML, Montana G, et al. Ferulic acid inhibits oxidative stress and cell death induced by Ab oligomers: improved delivery by solid lipid nanoparticles. Free Radic Res. 2009;43(11):1133-1145.

95. Sachdeva AK, Misra S, Pal Kaur I, Chopra K. Neuroprotective potential of sesamol and its loaded solid lipid nanoparticles in ICVSTZ-induced cognitive deficits: behavioral and biochemical evidence. Eur J Pharmacol. 2015;747:132-140.

96. Yusuf M, Khan M, Khan RA, Ahmed B. Preparation, characterization, in vivo and biochemical evaluation of brain targeted Piperine solid lipid nanoparticles in an experimentally induced Alzheimer's disease model. J Drug Target. 2012;21(3):300-311.

97. Barbu E, Molnar E, Tsibouklis J, Gorecki DC. The potential for nanoparticle-based drug delivery to the brain: overcoming the bloodbrain barrier. Expert Opin Drug Deliv. 2009;6(6):553-565.

98. Filipova M, Rusina R, Holada K. Nanoparticle-based drug delivery systems crossing blood-brain barrier - hope for future treatment of neurodegenerative disorders? Cesk Slov Neurol N. 2016;79(2):160-167.

99. Shah B, Khunt D, Bhatt H, Misra M, Padh H. Application of quality by design approach for intranasal delivery of rivastigmine loaded solid lipid nanoparticles: effect on formulation and characterization parameters. Eur J Pharm Sci. 2015;78:54-66.

100. Wilson CM, Magnaudeix A, Naves T, Vincent F, Lalloue F, Jauberteau MO. The ins and outs of nanoparticle technology in neurodegenerative diseases and cancer. Curr Drug Metab. 2015;16(8):609-632.

101. Zhang GL, Chen LK, Guo XY, Khan AA, Gu YC, Gu N. Nanoparticlemediated drug delivery systems (DDS) in the central nervous system. Curr Org Chem. 2017;21(3):272-283.

102. Dhawan S, Kapil R, Singh B. Formulation development and systematic optimization of solid lipid nanoparticles of quercetin for improved brain delivery. J Pharm Pharmacol. 2011;63(3):342-351.

103. Bondi ML, Montana G, Craparo EF, et al. Ferulic acid-loaded lipid nanostructures as drug delivery systems for Alzheimer's disease: preparation, characterization and cytotoxicity studies. Curr Nanosci. 2009;5(1):26-32.

104. Barbara R, Belletti D, Pederzoli F, et al. Novel curcumin loaded nanoparticles engineered for blood-brain barrier crossing and able to disrupt Abeta aggregates. Int J Pharm. 2017;526(1-2):413-424.

105. Battisti A, Piccionello AP, Sgarbossa A, et al. Curcumin-like compounds designed to modify amyloid beta peptide aggregation patterns RSC Adv. 2017;7(50):31714-31724.

106. Chandra B, Mithu VS, Bhowmik D, et al. Curcumin dictates divergent fates for the central salt bridges in amyloid- $\beta 40$ and amyloid- $\beta 42$. Biophys J. 2017;112(8):1597-1608.

107. Di Martino P, Censi R, Gigliobianco MR, et al. Nano-medicine improving the bioavailability of small molecules for the prevention of neurodegenerative diseases. Curr Pharm Des. 2017;23(13):1897-1908.

108. Jaroonwitchawan T, Chaicharoenaudomrung N, Natnkaew J, Noisa P. Curcumin attenuates paraquat-induced cell death in human neuroblastoma cells through modulating oxidative stress and autophagy Neurosci Lett. 2017;636:40-47.

109. Karimian MS, Pirro M, Johnston TP, Majeed M, Sahebkar A. Curcumin and endothelial function: evidence and mechanisms of protective effects. Curr Pharm Des. 2017;23(17):2462-2473.

110. McClure R, Ong H, Janve V, et al. Aerosol delivery of curcumin reduced amyloid- $\beta$ deposition and improved cognitive performance in a transgenic model of Alzheimer's disease. J Alzheimers Dis. 2017;55(2):797-811.
111. Ullah F, Liang A, Rangel A, Gyengesi E, Niedermayer G, Munch G. High bioavailability curcumin: an anti-inflammatory and neurosupportive bioactive nutrient for neurodegenerative diseases characterized by chronic neuroinflammation. Arch Toxicol. 2017;91(4):1623-1634.

112. Zeng Z, Shen ZL, Zhai S, et al. Transport of curcumin derivatives in Caco-2 cell monolayers. Eur J Pharm Biopharm. 2017;117: 123-131.

113. Kakkar V, Kaur IP. Evaluating potential of curcumin loaded solid lipid nanoparticles in aluminium induced behavioural, biochemical and histopathological alterations in mice brain. Food Chem Toxicol. 2011;49(11):2906-2913.

114. Ahmed T, Javed S, Javed S, et al. Resveratrol and Alzheimer's disease: mechanistic insights. Mol Neurobiol. 2017;54(4):2622-2635.

115. Cheng J, Rui Y, Qin L, et al. Vitamin D combined with resveratrol prevents cognitive decline in SAMP8 mice. Curr Alzheimer Res. 2017; 14(8):820-833.

116. Famenini S, Rigali EA, Olivera-Perez HM, et al. Increased intermediate M1-M2 macrophage polarization and improved cognition in mild cognitive impairment patients on omega-3 supplementation. FASEBJ. 2017;31(1):148-160.

117. He X, Li Z, Rizak JD, et al. Resveratrol attenuates formaldehyde induced hyperphosphorylation of Tau protein and cytotoxicity in $\mathrm{N} 2 \mathrm{a}$ cells. Front Neurosci. 2016;10:598.

118. Jerabek J, Uliassi E, Guidotti L, et al. Tacrine-resveratrol fused hybrids as multi-target-directed ligands against Alzheimer's disease. Eur J Med Chem. 2017;127:250-262.

119. Moussa C, Hebron M, Huang X, et al. Resveratrol regulates neuroinflammation and induces adaptive immunity in Alzheimer's disease. J Neuroinflammation. 2017;14(1):1.

120. Noratiqah SB, Naina-Mohamed I, Zulfarina MS, Qodriyah HM. Natural polyphenols in the treatment of Alzheimer's disease. Curr Drug Targets. Epub 2017 Mar 28.

121. Omar SH, Scott CJ, Hamlin AS, Obied HK. The protective role of plant biophenols in mechanisms of Alzheimer's disease. J Nutr Biochem. 2017;47:1-20.

122. Wightman EL. Potential benefits of phytochemicals against Alzheimer's disease. Proc Nutr Soc. 2017;76(2):106-112.

123. Xu P, Zhang M, Sheng R, Ma Y. Synthesis and biological evaluation of deferiprone-resveratrol hybrids as antioxidants, Abeta1-42 aggregation inhibitors and metal-chelating agents for Alzheimer's disease. Eur J Med Chem. 2017;127:174-186.

124. Cury RG, Fraix V, Castrioto A, et al. Thalamic deep brain stimulation for tremor in Parkinson disease, essential tremor, and dystonia. Neurology. 2017;89(13):1416-1423

125. Kanegusuku H, Silva-Batista C, Pecanha T, et al. Patients with Parkinson disease present high ambulatory blood pressure variability. Clin Physiol Funct Imaging. 2017;37(5):530-535.

126. Park J, Lee JW, Cooper SC, Broxmeyer HE, Cannon JR, Kim CH Parkinson disease-associated LRRK2 G2019S transgene disrupts marrow myelopoiesis and peripheral Th17 response. J Leukoc Biol. 2017; 102(4):1093-1102.

127. Ramirez AI, de Hoz R, Salobrar-Garcia E, et al. The role of microglia in retinal neurodegeneration: Alzheimer's disease, Parkinson, and glaucoma. Front Aging Neurosci. 2017;9:214.

128. Saez-Atienzar S, Singleton AB. Parkinson disease and clathrin coat dynamics at synapses, why not? Mov Disord. 2017;32(8):1163.

129. Son HJ, Jeong YJ, Yoon HJ, et al. Parkinson disease-related cortical and striatal cognitive patterns in dual time F-18 FP CIT: evidence for neural correlates between the caudate and the frontal lobe. $\mathrm{QJ} \mathrm{Nucl}$ Med Mol Imaging. Epub 2017 Jul 27.

130. Strupp J, Kunde A, Galushko M, Voltz R, Golla H. Severely affected by Parkinson disease: the patient's view and implications for palliative care. Am J Hosp Palliat Care. Epub 2017 Jan 1.

131. da Costa IM, Cavalcanti JRLP, de Queiroz DB, et al. Supplementation with herbal extracts to promote behavioral and neuroprotective effects in experimental models of Parkinson's disease: a systematic review. Phytother Res. 2017;31(7):959-970. 
132. Ganesan P, Ko HM, Kim IS, Choi DK. Recent trends in the development of nanophytobioactive compounds and delivery systems for their possible role in reducing oxidative stress in Parkinson's disease models. Int J Nanomedicine. 2015;10:6757-6772.

133. Gokul K, Muralidhara. Oral supplements of aqueous extract of tomato seeds alleviate motor abnormality, oxidative impairments and neurotoxicity induced by rotenone in mice: relevance to Parkinson's disease. Neurochem Res. 2014;39(7):1382-1394.

134. Guo H, Shi F, Li M, Liu Q, Yu B, Hu L. Neuroprotective effects of Eucommia ulmoides Oliv. and its bioactive constituent work via ameliorating the ubiquitin-proteasome system. BMC Complement Altern Med. 2015;15:151.

135. Klionsky DJ, Abdelmohsen K, Abe A, et al. Guidelines for the use and interpretation of assays for monitoring autophagy (3rd edition). Autophagy. 2016;12(1):1-222.

136. Mazo NA, Echeverria V, Cabezas R, et al. Medicinal plants as protective strategies against Parkinson's disease. Curr Pharm Des. 2017; 23(28):4180-4188

137. Morshedi D, Aliakbari F, Tayaranian-Marvian A, Fassihi A, PanMontojo F, Pérez-Sánchez H. Cuminaldehyde as the major component of Cuminum cyminum, a natural aldehyde with inhibitory effect on alpha-synuclein fibrillation and cytotoxicity. J Food Sci. 2015; 80(10):H2336-H2345.

138. Mythri RB, Harish G, Bharath MM. Therapeutic potential of natural products in Parkinson's disease. Recent Pat Endocr Metab Immune Drug Discov. 2012;6(3):181-200.

139. Nabavi SF, Braidy N, Habtemariam S, Sureda A, Manayi A, Nabavi SM. Neuroprotective effects of fisetin in Alzheimer's and Parkinson's diseases: from chemistry to medicine. Curr Top Med Chem. 2016;16(17): 1910-1915.

140. Pathak A, Srivastava AK, Singour PK, Gouda P. Synthetic and natural monoamine oxidase inhibitors as potential lead compounds for effective therapeutics. Cent Nerv Syst Agents Med Chem. 2016; 16(2):81-97

141. Solanki I, Parihar P, Mansuri ML, Parihar MS. Flavonoid-based therapies in the early management of neurodegenerative diseases. $A d v$ Nutr. 2015;6(1):64-72.

142. Cacciatore I, Ciulla M, Fornasari E, Marinelli L, Di Stefano A. Solid lipid nanoparticles as a drug delivery system for the treatment of neurodegenerative diseases. Expert Opin Drug Deliv. 2016;13(8):1121-1131.

143. Cunha S, Amaral MH, Lobo JM, Silva AC. Therapeutic strategies for Alzheimer's and Parkinson's diseases by means of drug delivery systems. Curr Med Chem. 2016;23(31):3618-3631.

144. Chen T, Deng Y, Liao X, et al. [Effect of curcumin on oligomer formation and mitochondrial ATP-sensitive potassium channels induced by overexpression or mutation of $\alpha$-synuclein]. Zhonghua Yi Xue Yi Chuan Xue Za Zhi. 2015;32(4):462-467. Chinese [with English abstract].

145. Cui Q, Li X, Zhu H. Curcumin ameliorates dopaminergic neuronal oxidative damage via activation of the Akt/Nrf2 pathway. Mol Med Rep. 2016;13(2):1381-1388.

146. Du XX, Xu HM, Jiang H, Song N, Wang J, Xie JX. Curcumin protects nigral dopaminergic neurons by iron-chelation in the 6-hydroxydopamine rat model of Parkinson's disease. Neurosci Bull. 2012;28(3):253-258.

147. Guerrero-Muñoz MJ, Castillo-Carranza DL, Kayed R. Therapeutic approaches against common structural features of toxic oligomers shared by multiple amyloidogenic proteins. Biochem Pharmacol. 2014; 88(4):468-478.

148. Phom L, Achumi B, Alone DP, Muralidhara, Yenisetti SC. Curcumin's neuroprotective efficacy in Drosophila model of idiopathic Parkinson's disease is phase specific: implication of its therapeutic effectiveness. Rejuvenation Res. 2014;17(6):481-489.

149. Song S, Nie Q, Li Z, Du G. Curcumin improves neurofunctions of 6-OHDA-induced parkinsonian rats. Pathol Res Pract. 2016; 212(4):247-251.
150. Spinelli KJ, Osterberg VR, Meshul CK, Soumyanath A, Unni VK. Curcumin treatment improves motor behavior in $\alpha$-synuclein transgenic mice. PLoS One. 2015;10(6):e0128510.

151. Uğuz AC, Öz A, Naziroğlu M. Curcumin inhibits apoptosis by regulating intracellular calcium release, reactive oxygen species and mitochondrial depolarization levels in SH-SY5Y neuronal cells. J Recept Signal Transduct Res. 2016;36(4):395-401.

152. Yu SY, Zhang M, Luo J, Zhang L, Shao Y, Li G. Curcumin ameliorates memory deficits via neuronal nitric oxide synthase in aged mice. Prog Neuropsychopharmacol Biol Psychiatry. 2013;45:47-53.

153. Abdel-Wahab WM. Thymoquinone attenuates toxicity and oxidative stress induced by bisphenol A in liver of male rats. Pak J Biol Sci. 2014;17(11):1152-1160.

154. Babu PR, Bhuvaneswar C, Sandeep G, Ramaiah CV, Rajendra W. Hepatoprotective role of Ricinus communis leaf extract against d-galactosamine induced acute hepatitis in albino rats. Biomed Pharmacother. 2017;88:658-666.

155. Dongiovanni $\mathrm{P}$, Lanti C, Riso P, Valenti L. Nutritional therapy for nonalcoholic fatty liver disease. J Nutr Biochem. 2016;29:1-11.

156. El-Hadary AE, Ramadan Hassanien MF. Hepatoprotective effect of cold-pressed Syzygium aromaticum oil against carbon tetrachloride (CCl4)-induced hepatotoxicity in rats. Pharm Biol. 2016;54(8): 1364-1372.

157. Fu YQ, Hua C, Zhou J, Cheng BR, Zhang J. Protective effects of ginseng total saponins against hepatic ischemia/reperfusion injury in experimental obstructive jaundice rats. Pharm Biol. 2013;51(12): $1545-1551$.

158. Huang HP, Ou TT, Wang CJ. Mulberry (sang shen zi) and its bioactive compounds, the chemoprevention effects and molecular mechanisms in vitro and in vivo. J Tradit Complement Med. 2013;3(1):7-15.

159. Inada AC, Figueiredo PS, Santos-Eichler RAD, et al. Morinda citrifolia Linn. (Noni) and its potential in obesity-related metabolic dysfunction. Nutrients. 2017;9(6).

160. Kowalska K, Olejnik A. Current evidence on the health-beneficial effects of berry fruits in the prevention and treatment of metabolic syndrome. Curr Opin Clin Nutr Metab Care. 2016;19(6):446-452.

161. Mopuri R, Islam MS. Medicinal plants and phytochemicals with anti-obesogenic potentials: a review. Biomed Pharmacother. 2017; 89:1442-1452.

162. Rodriguez-Ramiro I, Vauzour D, Minihane AM. Polyphenols and non-alcoholic fatty liver disease: impact and mechanisms. Proc Nutr Soc. 2016;75(1):47-60.

163. Samout N, Ettaya A, Bouzenna H, Ncib S, Elfeki A, Hfaiedh N. Beneficial effects of Plantago albicans on high-fat diet-induced obesity in rats. Biomed Pharmacother. 2016;84:1768-1775.

164. Valenti L, Riso P, Mazzocchi A, Porrini M, Fargion S, Agostoni C. Dietary anthocyanins as nutritional therapy for nonalcoholic fatty liver disease. Oxid Med Cell Longev. 2013;2013:145421.

165. Xu WH, Hu HG, Tian Y, et al. Bioactive compound reveals a novel function for ribosomal protein S5 in hepatic stellate cell activation and hepatic fibrosis. Hepatology. 2014;60(2):648-660.

166. Yu JY, Ha JY, Kim KM, Jung YS, Jung JC, Oh S. Anti-inflammatory activities of licorice extract and its active compounds, glycyrrhizic acid, liquiritin and liquiritigenin, in BV2 cells and mice liver. Molecules. 2015;20(7):13041-13054.

167. Abdelwahab SI, Sheikh BY, Taha MM, et al. Thymoquinone-loaded nanostructured lipid carriers: preparation, gastroprotection, in vitro toxicity, and pharmacokinetic properties after extravascular administration. Int J Nanomedicine. 2013;8:2163-2172.

168. Naseri N, Valizadeh H, Zakeri-Milani P. Solid lipid nanoparticles and nanostructured lipid carriers: structure, preparation and application. Adv Pharm Bull. 2015;5(3):305-313.

169. Rao MP, Manjunath K, Bhagawati ST, Thippeswamy BS. Bixin loaded solid lipid nanoparticles for enhanced hepatoprotection preparation, characterisation and in vivo evaluation. Int J Pharm. 2014; 473(1-2):485-492. 
170. Shuhendler AJ, Prasad P, Leung M, Rauth AM, Dacosta RS, Wu XY. A novel solid lipid nanoparticle formulation for active targeting to tumor $\alpha(v) \beta(3)$ integrin receptors reveals cyclic RGD as a doubleedged sword. Adv Healthc Mater. 2012;1(5):600-608.

171. Sharma AK, Kumar A, Kumar S, et al. Preparation and therapeutic evolution of Ficus benjamina solid lipid nanoparticles against alcohol abuse/antabuse induced hepatotoxicity and cardio-renal injury. $R S C$ Adv. 2017;7(57):35938-35949.

172. Kakkar V, Mishra AK, Chuttani K, Chopra K, Kaur IP. Delivery of sesamol-loaded solid lipid nanoparticles to the brain for menopauserelated emotional and cognitive central nervous system derangements. Rejuvenation Res. 2011;14(6):597-604.

173. Elzoghby AO, Abd-Elwakil MM, Abd-Elsalam K, Elsayed MT, Hashem Y, Mohamed O. Natural polymeric nanoparticles for braintargeting: implications on drug and gene delivery. Curr Pharm Des. 2016;22(22):3305-3323.

174. Fonte P, Andrade F, Araújo F, Andrade C, Neves JD, Sarmento B Chitosan-coated solid lipid nanoparticles for insulin delivery. Methods Enzymol. 2012;508:295-314.

175. Luo Y, Teng Z, Li Y, Wang Q. Solid lipid nanoparticles for oral drug delivery: chitosan coating improves stability, controlled delivery, mucoadhesion and cellular uptake. Carbohyd Polym. 2015;122:221-229.

176. Baek JS, Cho CW. Surface modification of solid lipid nanoparticles for oral delivery of curcumin: improvement of bioavailability through enhanced cellular uptake, and lymphatic uptake. Eur J Pharm Biopharm. 2017;117:132-140.

177. Campos J, Varas-Godoy M, Haidar ZS. Physicochemical characterization of chitosan-hyaluronan-coated solid lipid nanoparticles for the targeted delivery of paclitaxel: a proof-of-concept study in breast cancer cells. Nanomedicine (Lond). 2017;12(5):473-490.

178. Nguyen HM, Hwang IC, Park JW, Park HJ. Photoprotection for deltamethrin using chitosan-coated beeswax solid lipid nanoparticles. Pest Manag Sci. 2012;68(7):1062-1068.

179. Rassu G, Soddu E, Posadino AM, et al. Nose-to-brain delivery of BACE1 siRNA loaded in solid lipid nanoparticles for Alzheimer's therapy. Colloids Surf B Biointerfaces. 2017;152:296-301.

180. Wang JY, Wang Y, Meng X. Chitosan nanolayered cisplatin-loaded lipid nanoparticles for enhanced anticancer efficacy in cervical cancer. Nanoscale Res Lett. 2016;11(1):524.

181. Thakkar A, Chenreddy S, Wang J, Prabhu S. Ferulic acid combined with aspirin demonstrates chemopreventive potential towards pancreatic cancer when delivered using chitosan-coated solid-lipid nanoparticles. Cell Biosci. 2015;5:46.

182. Thakkar A, Chenreddy S, Thio A, Khamas W, Wang J, Prabhu S. Preclinical systemic toxicity evaluation of chitosan-solid lipid nanoparticle-encapsulated aspirin and curcumin in combination with free sulforaphane in BALB/c mice. Int J Nanomedicine. 2016;11:3265-3276.

183. Fathi M, Mirlohi M, Varshosaz J, Madani G. Novel caffeic acid nanocarrier: production, characterization, and release modeling. J Nanomater. 2013;2013:434632.
184. Chen F, Zhang ZR, Yuan F, Qin X, Wang M, Huang Y. In vitro and in vivo study of N-trimethyl chitosan nanoparticles for oral protein delivery. Int J Pharm. 2008;349(1-2):226-233.

185. Han L, Tang C, Yin C. Oral delivery of shRNA and siRNA via multifunctional polymeric nanoparticles for synergistic cancer therapy. Biomaterials. 2014;35(15):4589-4600.

186. Zhang J, Tang C, Yin C. Galactosylated trimethyl chitosan-cysteine nanoparticles loaded with Map4k4 siRNA for targeting activated macrophages. Biomaterials. 2013;34(14):3667-3677.

187. Shi LL, Lu J, Cao Y, et al. Gastrointestinal stability, physicochemical characterization and oral bioavailability of chitosan or its derivativemodified solid lipid nanoparticles loading docetaxel. Drug Dev Ind Pharm. 2017;43(5):839-846.

188. Cai J, Dang Q, Liu C, et al. Preparation, characterization and antibacterial activity of O-acetyl-chitosan-N-2-hydroxypropyl trimethyl ammonium chloride. Int J Biol Macromol. 2015;80:8-15.

189. Li GF, Wang JC, Feng XM, Liu ZD, Jiang CY, Yang JD. Preparation and testing of quaternized chitosan nanoparticles as gene delivery vehicles. Appl Biochem Biotechnol. 2015;175(7):3244-3257.

190. Xiao B, Ma P, Ma L, et al. Effects of tripolyphosphate on cellular uptake and RNA interference efficiency of chitosan-based nanoparticles in Raw 264.7 macrophages. J Colloid Interface Sci. 2017;490 520-528.

191. Yang Z, Shang Y, Huang X, et al. Cationic content effects of biodegradable amphoteric chitosan-based flocculants on the flocculation properties. J Environ Sci (China). 2012;24(8):1378-1385.

192. Zhao K, Sun Y, Chen G, et al. Biological evaluation of N-2hydroxypropyl trimethyl ammonium chloride chitosan as a carrier for the delivery of live Newcastle disease vaccine. Carbohydr Polym. 2016;149:28-39.

193. Shi LL, Xie H, Lu J, et al. Positively charged surface-modified solid lipid nanoparticles promote the intestinal transport of docetaxel through multifunctional mechanisms in rats. Mol Pharm. 2016; 13(8):2667-2676.

194. Rezzani R, Rodella LF, Fraschini F, et al. Melatonin delivery in solid lipid nanoparticles: prevention of cyclosporine A induced cardiac damage. J Pineal Res. 2009;46(3):255-261.

195. Karthivashan G, Ganesan P, Park S, Kim J, Choi D. Therapeutic strategies and nano-drug delivery applications in management of ageing Alzheimer's disease. Drug delivery. 2018;25(1):307-320.

196. Sayin B, Somavarapu S, Li XW, Sesardic D, Senel S, Alpar OH TMC-MCC (N-trimethyl chitosan-mono-N-carboxymethyl chitosan) nanocomplexes for mucosal delivery of vaccines. Eur J Pharm Sci. 2009;38(4):362-369

197. Yin L, Ding J, He C, Cui L, Tang C, Yin C. Drug permeability and mucoadhesion properties of thiolated trimethyl chitosan nanoparticles in oral insulin delivery. Biomaterials. 2009;30(29):5691-5700.

198. Slütter B, Soema PC, Ding Z, Verheul R, Hennink W, Jiskoot W. Conjugation of ovalbumin to trimethyl chitosan improves immunogenicity of the antigen. J Control Release. 2010;143(2):207-214.
International Journal of Nanomedicine

\section{Publish your work in this journal}

The International Journal of Nanomedicine is an international, peerreviewed journal focusing on the application of nanotechnology in diagnostics, therapeutics, and drug delivery systems throughout the biomedical field. This journal is indexed on PubMed Central, MedLine, CAS, SciSearch $®$, Current Contents $\AA /$ Clinical Medicine,

\section{Dovepress}

Journal Citation Reports/Science Edition, EMBase, Scopus and the Elsevier Bibliographic databases. The manuscript management system is completely online and includes a very quick and fair peer-review system, which is all easy to use. Visit http://www.dovepress.com/ testimonials.php to read real quotes from published authors. 